\title{
Considerations on the Stiffness of Sensitive Soft Soils
}

\author{
Lamia Touiti $^{1(\bowtie)}$ and William Van Impe ${ }^{2}$ \\ ${ }^{1}$ LGC, Civil Engineering Laboratory - Ecole Nationale d'Ingénieurs de Tunis, \\ Université de Tunis El Manar, Tunis, Tunisia \\ touiti.1@gmail.com \\ 2 ISSMGE, Ghent University Belgium, Gent, Belgium
}

\begin{abstract}
The present paper comments on the evaluation of the initial stiffness of sensitive soft soils as an outcome of several testing methods: Resonant Column (RC), Bender Element (BE) tests, Seismic cone tests and Empirical relationships (correlations). The RC, BE and common geotechnical laboratory tests were carried out on soft clays adjacent to the Tunis Lake in Tunisia. The database was completed making use of existing studies carried out on other types of Swedish soft clays from the literature related to seismic cone tests. A number of empirical correlations for determining the initial value of the shear modulus of soils in the literature was adopted in order to re-analyze the available data set. The authors suggested an adapted empirical lower bound correlation aiming at evaluating the analyzed soft soils' small strain shear modulus $\left(\mathrm{G}_{\max }\right)$, probably even useful for less undisturbed sampling. The proposed equation aims at giving an indication of the effect of, for example, the mean effective stress ( $\left.\mathrm{p}^{\prime}\right)$ and the corresponding void ratio (e) on the initial soil stiffness more clearly.
\end{abstract}

\section{Introduction}

The small strain shear modulus $\left(\mathrm{G}_{\max }\right)$ of soil is an important parameter for a large variety of geotechnical design problems. Such modulus is typically associated with shear strain levels of about $10^{-4} \%$ and below. The critical role of soil stiffness at small-strains in the design and analysis of geotechnical structures is widely accepted. For example, $\mathrm{G}_{\max }$ is a key parameter in small-strain static and dynamic analyses (certainly covering foundation engineering problems such as those related to earthquake, wind power plants, machine foundations or rail/road traffic...) (Schnaid 2005; Stokoe et al. 2005). $\mathrm{G}_{\max }$ can be equally important for small-strain cyclic situations (wind or wave loading).

$\mathrm{G}_{\max }$ is reasonably well connected also to other soil properties, such as density and sample disturbance (Nash 1999). Its value depends on a number of parameters, including void ratio, confining stress, soil structure, degree of saturation, stress history and time factors. Table 1 shows a list of parameters affecting $\mathrm{G}_{\max }$ at different levels of importance, originally listed by Vucetic and Dobry (1991) and updated by Benz (2007). As shown in this table, the most important parameters affecting the soft soils small-strain stiffness are confining pressure, void ratio, geologic age, cementation, overconsolidation ratio, plasticity index as well as the frequency of a loading pattern. 
Table 1. Parameters affecting the small-strain stiffness of soils (Theenathayarl (2011), modified from the original table presented by Vucetic and Dobry (1991))

\begin{tabular}{l|l}
\hline Increasing factor & Gmax \\
\hline Confining pressure $\left(\sigma^{\prime} \mathrm{m}\right)$ & Increases with $\left(\sigma^{\prime} \mathrm{m}\right)$ \\
\hline Void ratio (e) & Decreases with e \\
\hline Geologic age $(\mathrm{tg})$ & Increases with tg \\
\hline Cementation $(\mathrm{c})$ & Increases with c \\
\hline OCR & Increases with OCR \\
\hline Plasticity Index (PI) & Increases with PI if OCR > 1 \\
\cline { 2 - 2 } & Stays constant if OCR = 1 \\
\hline Cyclic strain $(\gamma \mathrm{c})$ & - \\
\hline Frequency of loading (f) & Increases with f \\
\hline
\end{tabular}

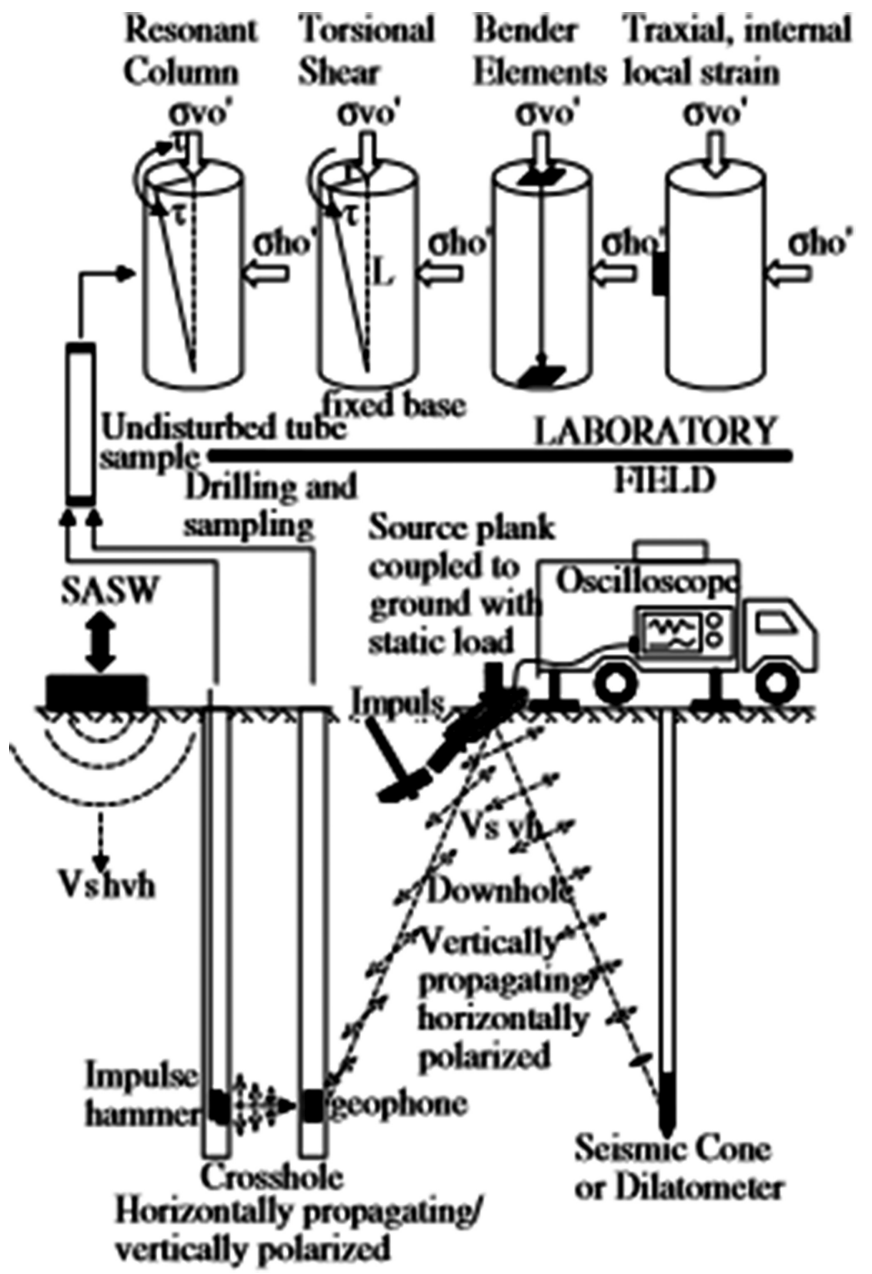

Fig. 1. Field and laboratory methods for determining shear modulus (Shneider et al. 1999). 
It is common practice to qualify a reliable value of $\mathrm{G}_{\max }$ of the soil (at induced strain levels less than $0.0001 \%$ ) from the shear wave velocity:

$$
\mathrm{G}_{0}=\mathrm{V}_{\mathrm{s}}^{2} \cdot \rho, \mathrm{kPa}
$$

Where: G0 = Initial shear modulus; $\rho=$ mass density; Vs = shear waves velocity for a linear, elastic and isotropic medium.

Most testing techniques are consisting of a combination of standard geotechnical tests with the geophysical modulus used both in laboratory and field conditions. Such hybrid (field/lab) method is shown in Fig. 1 (Schneider et al. 1999). Field techniques, besides of the seismic cone (SCPTU) and seismic flat dilatometer, include cross hole and down hole tests in the typical geophysical version and the SASW method. Laboratory tests in turn, are described as the resonant column (RC), torsional shear and triaxial tests with local strain measurement and the measurement of the shear wave velocity based on bender element (BE). Such configurations diminish the disadvantages of each group of tests and considerably enhance the optimization of data collection (Wolski et al. 2006).

The focus of this paper is to evaluate the $G_{\max }$ using $R C, B E$ and seismic cone test results verifying some empirical formulas, from literature and adding own test results. The analyzed data correspond to both laboratory tests conducted on Tunis soft soil (RC and bender BE tests) and collected data related to Swedish soft soils (laboratory tests and seismic cone as field tests). Having analyzed the results, the authors suggest an adapted correlation which fits well the sensitive soils.

\section{Materials and Methods}

\subsection{Tunis Soft Soils}

The soil for laboratory tests, sampled as "undisturbed" standard tube samples, was collected from the region close to the Tunis Lake in Tunisia, more specifically, from the test sites located in and near the Ghana avenue (south lake). The soil samples can be described as gray-black soft silty clay and do belong to a natural cohesive soil formation, of recent Quaternary origin, deposited in a marine environment. The deposit qualifies as a normally consolidated soft soil with illite as the dominating clay and quartz in the silt particles (Kaâniche et al. 2000; Touiti et al. 2009).

All laboratory tests were carried out at the Geotechnical Institute for Experimental Models (ISMGEO Laboratory) in Italy and at the Geotechnical laboratory of the Ghent University (Belgium). The test results summarized in Table 2 do show a clay and silt content of about $40 \%$, an organic content in the range of 2 to $5 \%$, a water content from 84 to $110 \%$ (slightly above the liquid limit), an undrained shear strength derived from TXCIU tests from 15 to $28 \mathrm{kPa}$ and $\mathrm{G}_{\max }$, determined using RC and BE tests, in the range of 3 to $8 \mathrm{MPa}$. The sensitivity of the Tunis soft soils samples and the one at the Ska-Edeby site was estimated on the basis of the liquidity index (LI) and the undrained shear strength $(\mathrm{Cu})$, as established by Leroueil et al. (1983): 
Table 2. Identification and soil index properties of selected Tunis soft soils

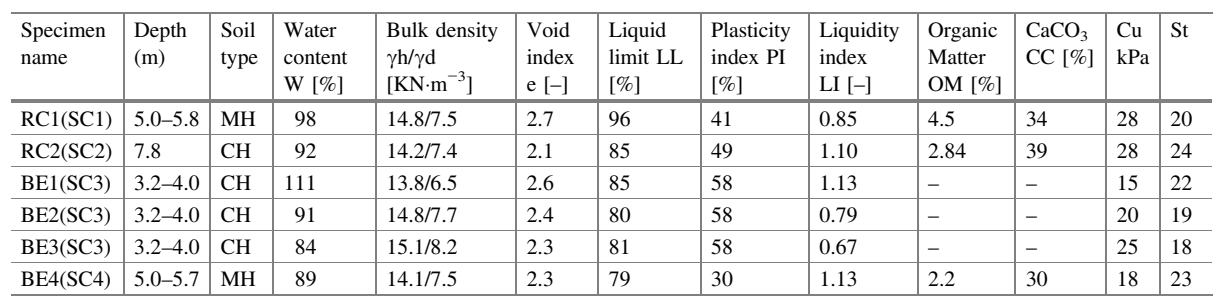

$$
\begin{gathered}
C u_{r}(k P a)=\frac{1}{\left(I_{L}-0.21\right)^{2}} \\
S t=C u\left(I_{L}-0.21\right)^{2}
\end{gathered}
$$

The sensitivity of Tunis soft soils ranged from 18 to 24 .

\subsubsection{Resonant Column Tests}

The RC tests were performed using the ISMGEO laboratory Resonant Column Apparatus $(4-100 \mathrm{~Hz})$ which is an example of Hardin-Drnevich resonant column using "fixed-free" configuration (Fig. 2). This equipment is commonly used to study the dynamic deformation characteristics of soil.
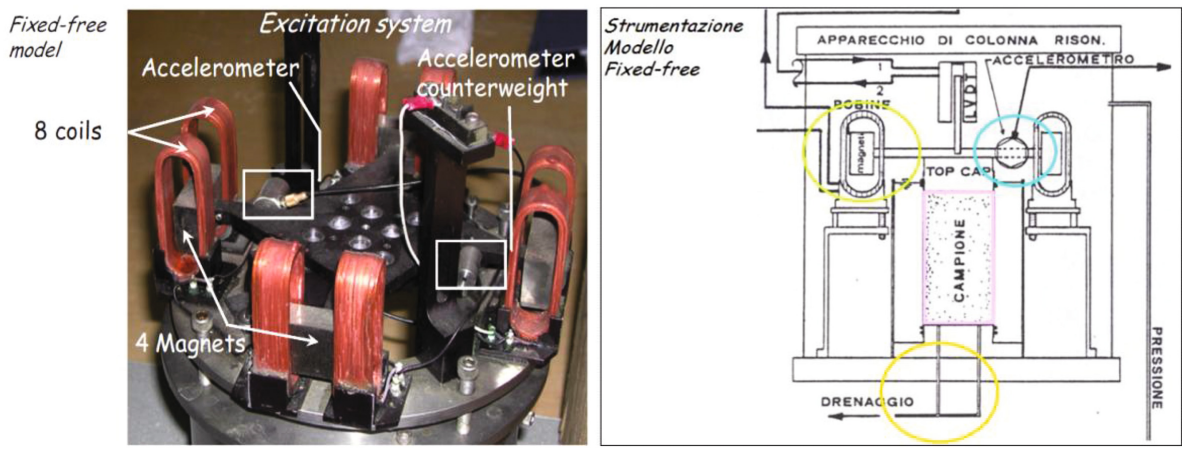

Fig. 2. Resonant column apparatus used for the tests - ISMGEO laboratory - Italy

The procedure for testing the soils with $\mathrm{RC}$ method followed that outlined in ASTM D 4015-07. In fact, the specimen is rigidly fixed at the base while the torsional oscillation is applied to the free end by a drive head. The frequency of vibration is gradually increased until reaching the first-mode fundamental frequency of the sample, at which measurements of the resonance frequency and amplitude of vibration are made. Knowing the geometry and the end constraints of the sample, the measured resonance frequency is then used to calculate the shear wave propagation velocity using the wave propagation equation and the theory of elasticity. The shear modulus is subsequently obtained from the derived shear wave velocity and the density of the sample. 


\subsubsection{Bender Element Tests}

The triaxial tests were performed on 6 undisturbed Tunis soft soil specimen in three stages: saturation (back pressure method), consolidation and shearing (strain controlled mode).

The bender elements are small electro-mechanical transducers which either bend as an applied voltage is changed or generate the voltage as they bend. Bender elements were placed into soil sample during the triaxial tests (Fig. 3). The measurements of the shear wave velocity were performed at the end of each of the saturation and consolidation stage during triaxial tests (Fig. 3). In order to rule out the incorrect measurements, additional measurements of the travel time at the same stress condition but with different frequency of input signal were made.
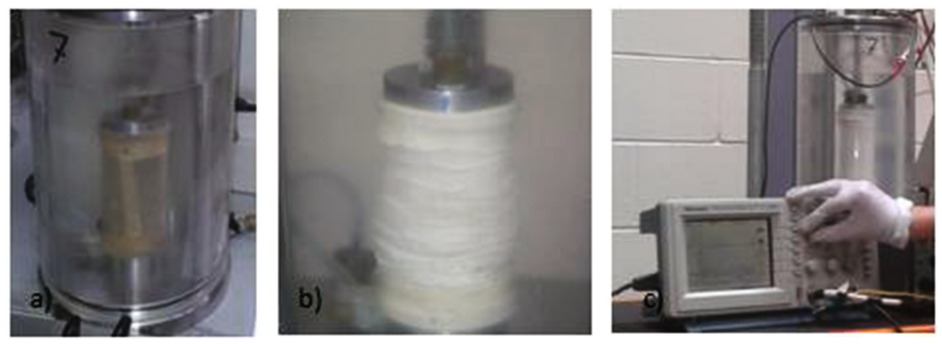

Fig. 3. (a) Tunis soft soil samples wrapped in filter paper and rubber skin. (b) Bender elements placed into Tunis soft soil sample (c) Triaxial apparatus equipped with bender elements used for the tests

\subsection{Swedish Soft Soils}

A geotechnical soft soil database including stiffness properties measured by seismic cone tests was elaborated. The data base was completed on the basis of several investigations and studies performed on Swedish soft soils (Larsson and Mulabdic 1991).

The analyzed Swedish test sites were selected among the well documented test fields previously used by the Swedish Geotechnical Institute (SGI): Skå-Edeby, Norrköping and Bäckebol sites. The soft soils at those sites have a thickness of 5 to $10 \mathrm{~m}$ predominantly marine post-glacial clay with the presence of shells and thin layers or seams of silt.

The natural water content is generally higher than the liquid limit. The sensitivity of the clays varies between 8 and 24. The undrained shear strength as determined by field vane tests reaches a minimum of 7.5 to $9 \mathrm{kPa}$ at $2 \mathrm{~m}$ below the ground surface for the various sites and seems to increase with depth.

The geotechnical parameters of the various sites are summarized in the Table 3.

Table 3. Geotechnical parameters of selected Swedish soft soils

\begin{tabular}{l|c|c|l|l|l|l|l|l|l|l|l}
\hline Site & $\mathrm{Z}(\mathrm{m})$ & $\mathrm{W}(\%)$ & $\mathrm{WL}(\%)$ & $\mathrm{IP}(\%)$ & $\mathrm{P}^{\prime}(\mathrm{kPa})$ & $\mathrm{e}$ & $\mathrm{Cu}(\mathrm{kPa})$ & $\mathrm{OC}(\%)$ & $\mathrm{St}$ & $\mathrm{Vs} \mathrm{m} / \mathrm{s}$ & $\mathrm{OCR}$ \\
\hline Norrköping & $3-10$ & $70-118$ & $62-84$ & - & $33-50$ & $1.7-3.3$ & $9-15$ & - & $10-20$ & $66-98$ & $1.2-1.6$ \\
\hline Skå-Edeby site & $3-9$ & $64-87$ & $55-83$ & $30-56$ & $17-38$ & $1.7-2.4$ & $8-15$ & $1-5$ & $6-16$ & - & $1.1-1.2$ \\
\hline Bäckebol site & $2-8$ & $78-100$ & $69-86$ & $36-51$ & $22-37$ & $2.0-2.7$ & $11-15$ & $<1 \%$ & $12-24$ & $56-85$ & $1.2-1.9$ \\
\hline
\end{tabular}




\subsubsection{Norrköping Site}

According to Larson and Mulabdic (1991), the investigated soil profile consists of about 8 meters of gray varved clay $(2-10 \mathrm{~m})$ with thin layers or seams of silt which occur at about $5 \mathrm{~m}$ and do appear even more regular from $7 \mathrm{~m}$ depth on. The natural water content is higher than the liquid limit and varies from $120 \%$ at the upper layers to about $70 \%$ in the silty bottom layers. The soil is slightly over consolidated; the over consolidation ratio ranges from 1.2 to 1.6. The sensitivity of the clay measured with the field vane tests varies between 10 and 20. The small strain shear modulus deduced from the seismic cone tests ranges from 5 to $15 \mathrm{MPa}$.

\subsubsection{Skå-Edeby Site}

The test field is located on Svartsjölandet. A large number of tests has been made in that test field at Ska-Edeby (Kallstenius and Bergau 1961; Kallstenius 1963; oysterman and Lindskog 1963; Push 1970; Holtz and Linkskog 1972; Holtz and Broms 1972; Holtz and Holm 1972; BomanandBroms 1975; Wiezel 1975; Massarsch et al. 1975; Torstensson 1976; Holm and Holtz 1977; Larsson 1986; Larsson and Eskilson 1989; Larsson and Mulabdic 1991).

According to the above-mentioned studies, the soil profile $(3-9 \mathrm{~m})$ consists of $3 \mathrm{~m}$ of post-glacial clay, highly plastic and slightly organic, followed by $6 \mathrm{~m}$ of varved glacial clay. For both layers, the water content is higher than the liquid limit, the soil is slightly overconsolidated (OCR $=1.1$ to 1.2 ), the undrained shear strength (field vane testing) increases with depth from $8 \mathrm{kPa}$ to $14 \mathrm{kPa}$, the sensitivity varies from 6 to 16 and is common of 15 and the small strain shear modulus (seismic cone tests) varies with depth from $3 \mathrm{MPa}$ to $14 \mathrm{MPa}$ showing a uniform and continuous increase.

\subsubsection{Bäckebol Site}

The test field is located near the river GötaÄlv and concerns mainly the upper $10 \mathrm{~m}$ of the soil site. According to Larrsson and Mulabdic (1991), the clay consists of post glacial marine clay, with illite as the dominating clay mineral and quartz and feldspar in the silt particles, the clay content being about $60 \%$, the organic content less than $1 \%$, the water content reaching some 70 to $90 \%$ which is slightly above the liquid limit.

The undrained shear strength varies between 11 to $15 \mathrm{kPa}$, its sensitivity shows values ranging from 12 to 24 and the small strain shear modulus derived from the seismic cone tests varies from 5 to $11 \mathrm{MPa}$.

\section{Interpretation and Discussion of RC and BE Test Results and Collected Data}

\subsection{Tunis Soft Soils}

The results obtained in the laboratory from BE and RC tests are presented in Figs. 4 and 5 . The values of the shear wave velocity and the small strain shear modulus varied from 40 to $80 \mathrm{~m} / \mathrm{s}$ and 3 to $8 \mathrm{MPa}$ respectively at an applied mean effective stress ranging from 10 to $50 \mathrm{kPa}$. 


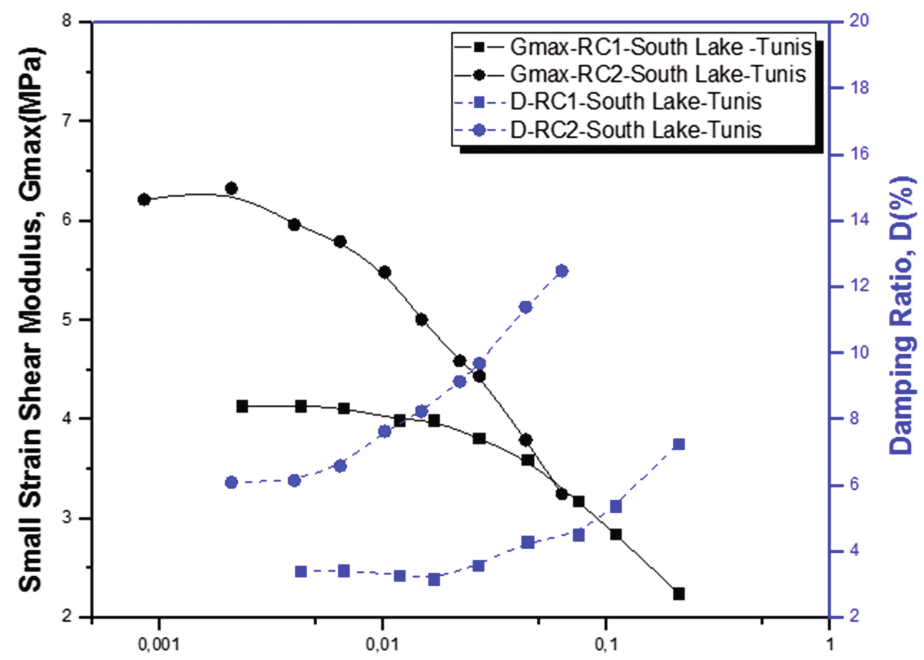

Shear Strain, $\gamma(\%)$

Fig. 4. Shear modulus and damping ratio for Tunis soft soil

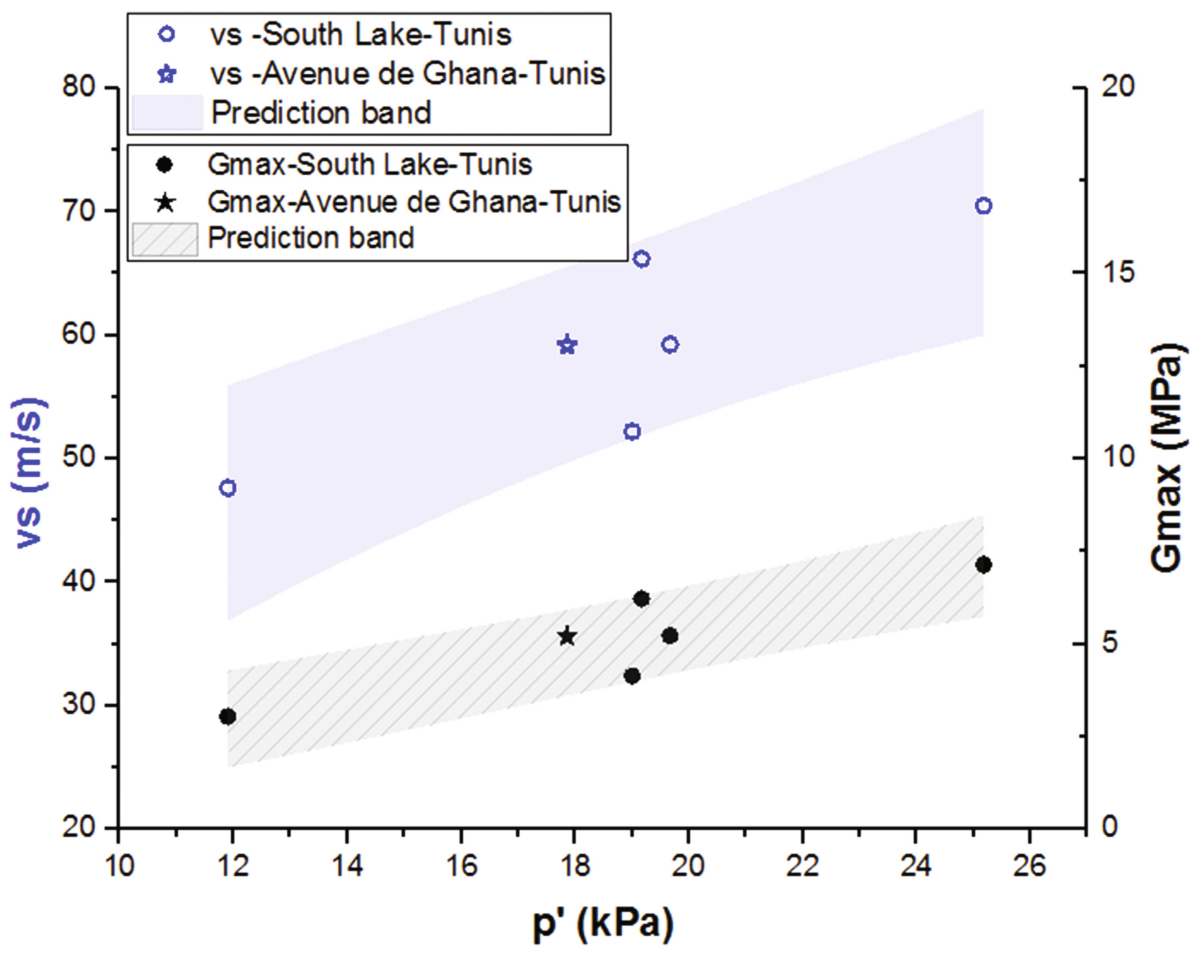

Fig. 5. Small strain shear modulus and shear wave velocity vs. mean effective stress for Tunis soft soils 
The relationship between the estimated shear modulus, the mean effective stress and the void ratio for tested soft soils (Fig. 6) confirm the positive impact of the mean effective stress and the negative impact of voids on the $G_{\max }$.

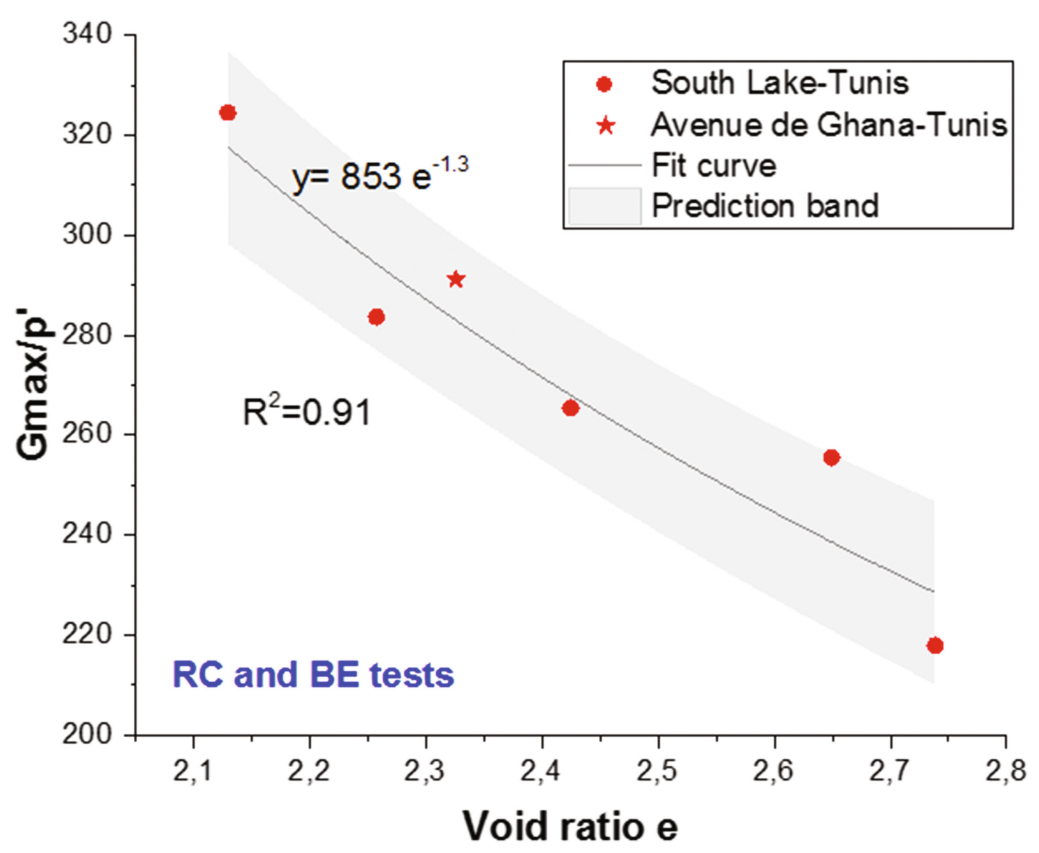

Fig. 6. Normalized Gmax/p' deduced from authors' bender element and resonant column tests versus void ratio for Tunis soft soils

\subsection{Swedish Soft Soils}

The mean effective stress and the void ratio were calculated and deduced based on the collected data related to Swedish soft soils from the test fields in Norrköping, SkåEdeby and Bäckebol sites.

The small strain shear modulus versus the mean effective stress and the void ratio for the different Swedish sites was elaborated. Swedish soft soil stiffness properties resulting from seismic cone tests were collected and re-interpreted as well and summarized in Table 4.

Table 4. The stiffness parameters of selected Swedish soft soils

\begin{tabular}{l|l|l}
\hline Gmax $(\mathrm{MPa})$ & e & $\mathrm{P}^{\prime}(\mathrm{kPa})$ \\
\hline $3-15$ & $1.8-3.4$ & $17-50$ \\
\hline
\end{tabular}




\subsubsection{Norrköping Site}

The small strain shear modulus versus the mean effective stress and the small strain shear modulus versus the void ratio are illustrated in Figs. 7 and 8.

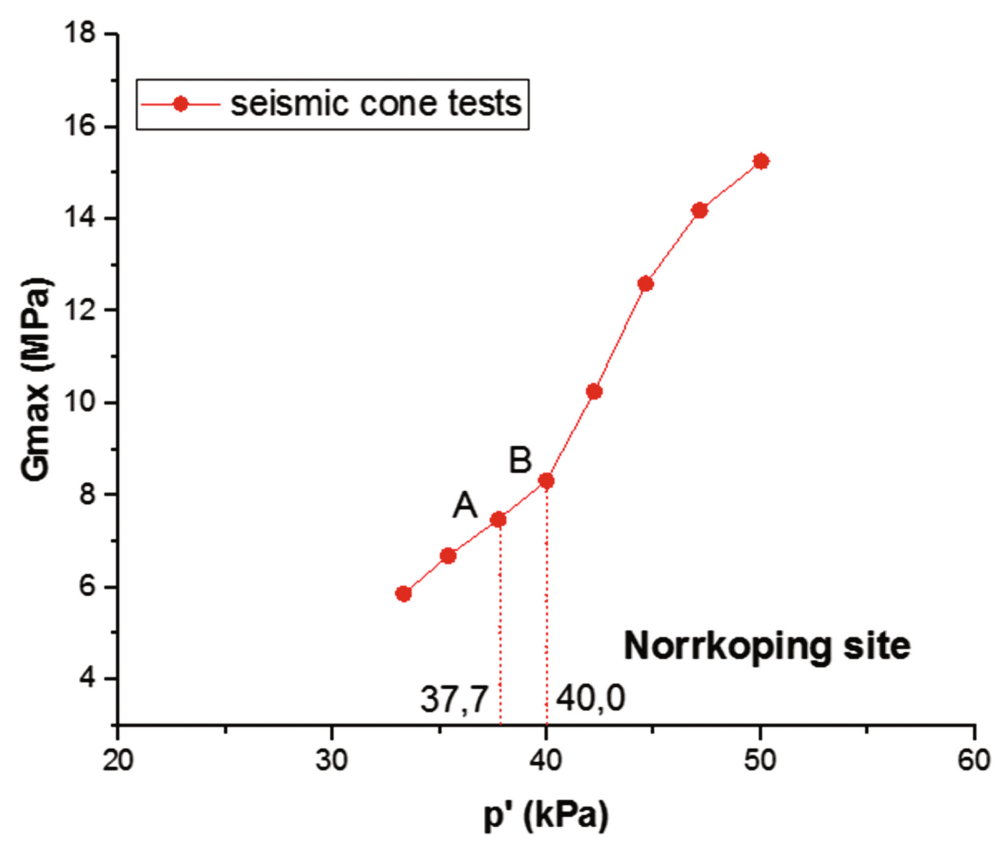

Fig. 7. Small strain shear modulus versus mean effective stress for sensitive soils in Norrköping

The singular points (A and B) at depths of 5 and $6 \mathrm{~m}(37.7$ and $39.98 \mathrm{kPa})$, are indicating a change of the curving slope and a greater stiffness of the soil. This is probably due to the presence of 3 different layers: the first layer from 3 to $5 \mathrm{~m}$ corresponding to soft clay, the second one, from 5 to $7 \mathrm{~m}$, related to the irregular varved clay with thin silt layers and the third layer appearing from 7 to $10 \mathrm{~m}$ and corresponding to the regular varved clay.

\subsubsection{Skå-Edeby Site}

The small strain shear modulus versus the mean effective stress (Fig. 9) illustrates a uniform and linear relation for each soft clay layer while the standardized small strain shear modulus versus the void ratio suggests a non-linear but continuous relationship (Fig. 10), except for 1 isolated point (C) at $6 \mathrm{~m}$ depth. This can possibly be explained by the presence of a thin seam with quite deviating geotechnical characteristics. 


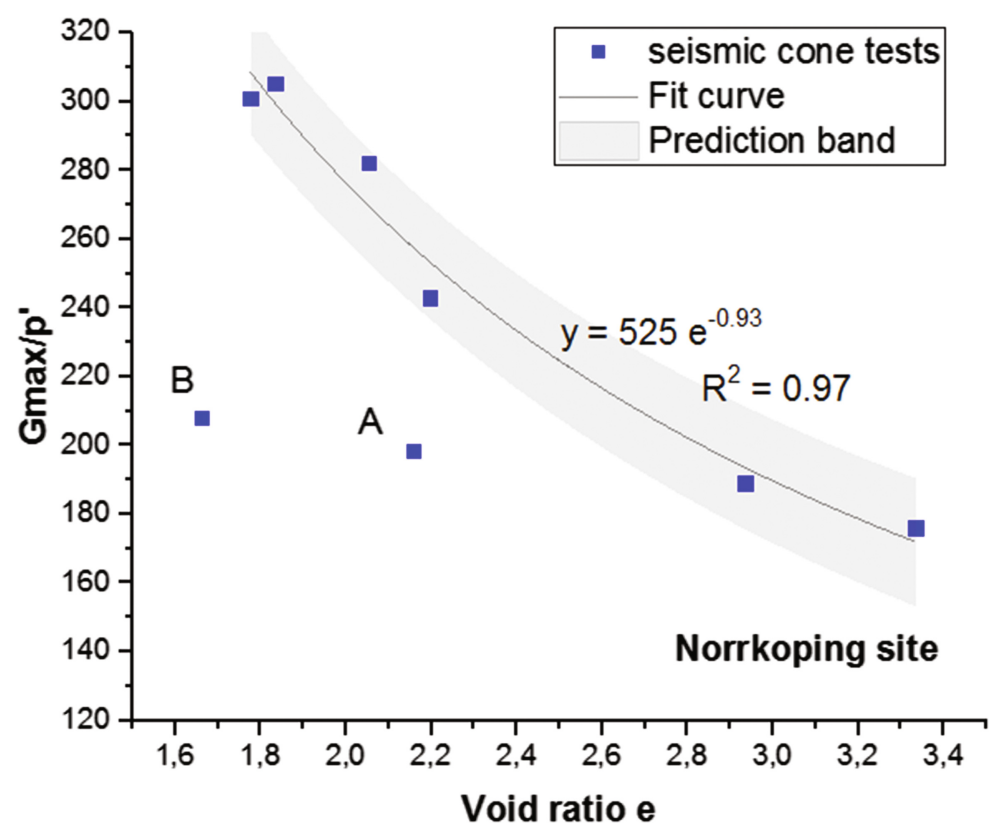

Fig. 8. Normalized small strain shear modulus versus mean effective stress for sensitive soils in Norrköping

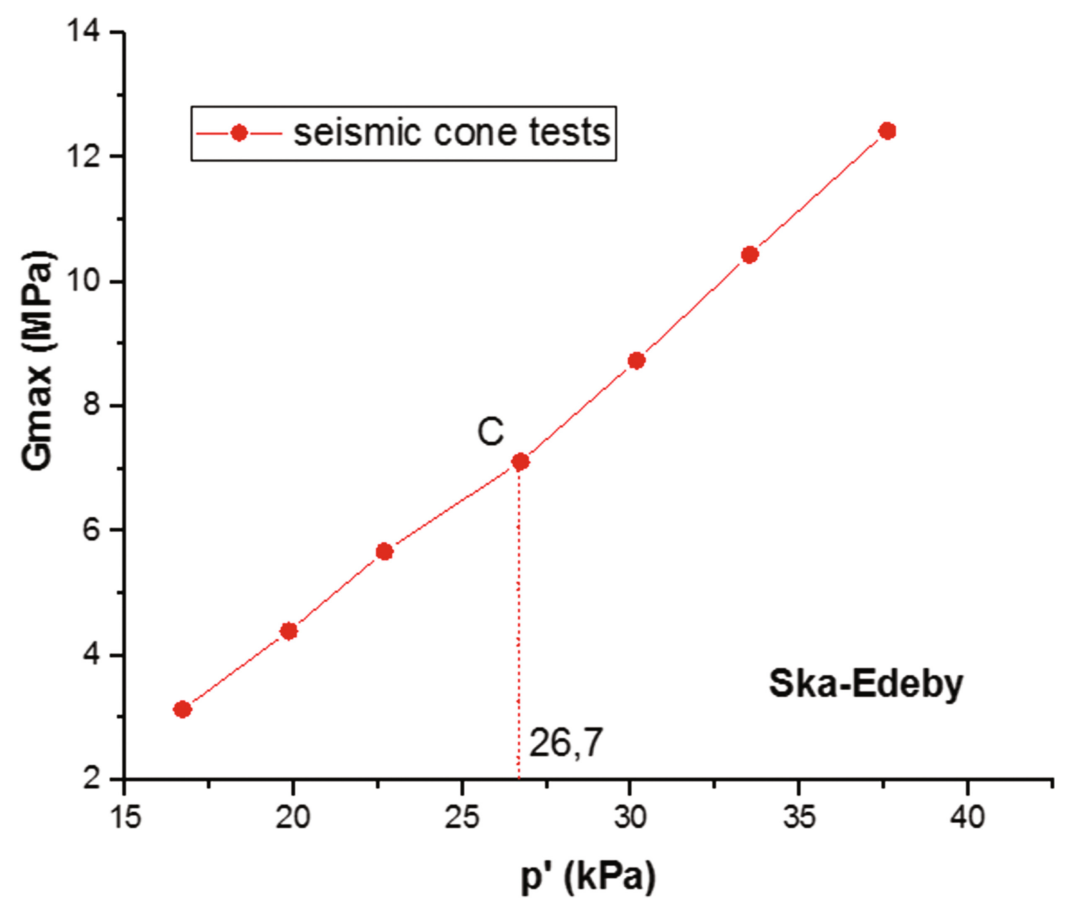

Fig. 9. Small strain shear modulus versus mean effective stress for sensitive soils in Skå-Edeby 


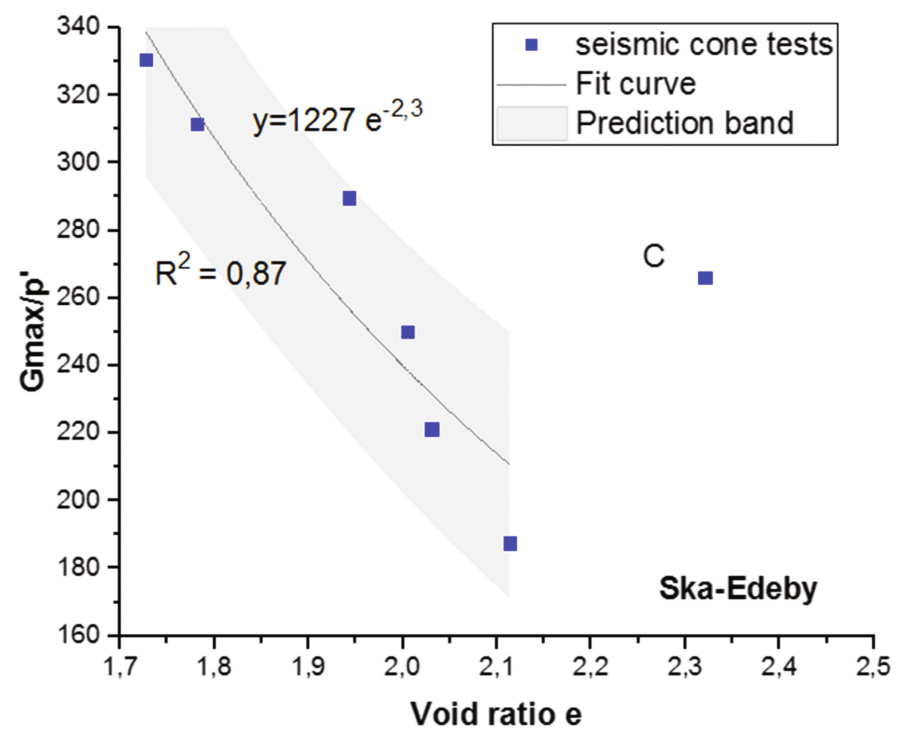

Fig. 10. Normalized small strain shear modulus versus mean effective stress for sensitive soils in Skå-Edeby

\subsubsection{Bäckebol Site}

Figures 11 and 12 do show a very straightforward relationship between the small strain shear modulus, the mean effective stress and the void ratio, with the exception of 2 isolated points (D and $\mathrm{E}$ ) at 5 and $6 \mathrm{~m}$, respectively. This can possibly be explained by the presence of a thin seam of other geotechnical characteristics.

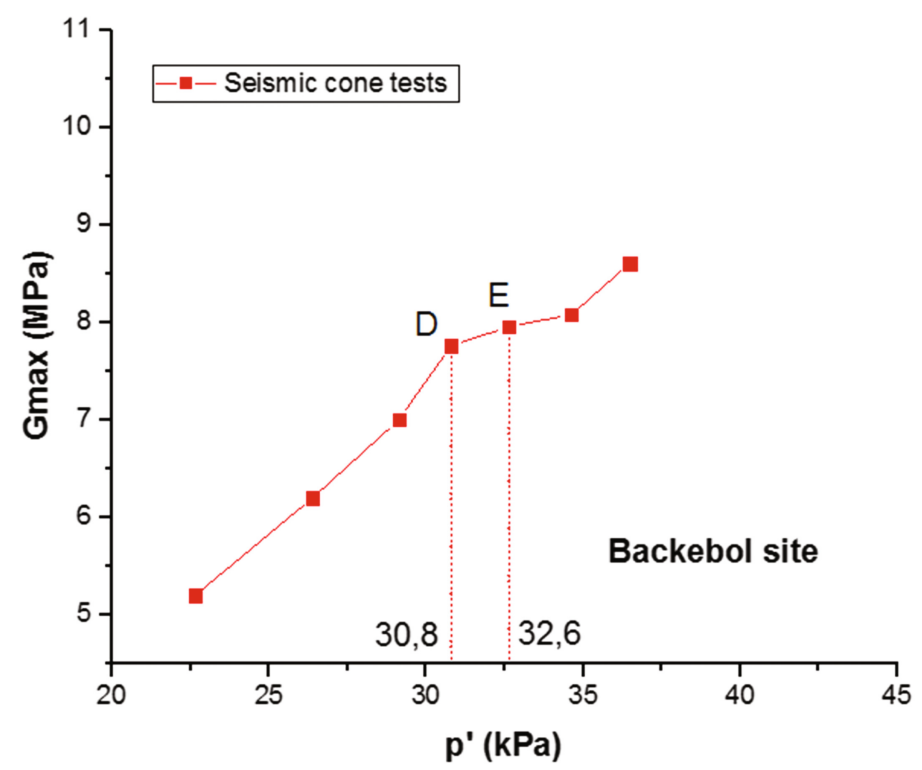

Fig. 11. Small strain shear modulus versus mean effective stress for sensitive soils in Bäckebol 


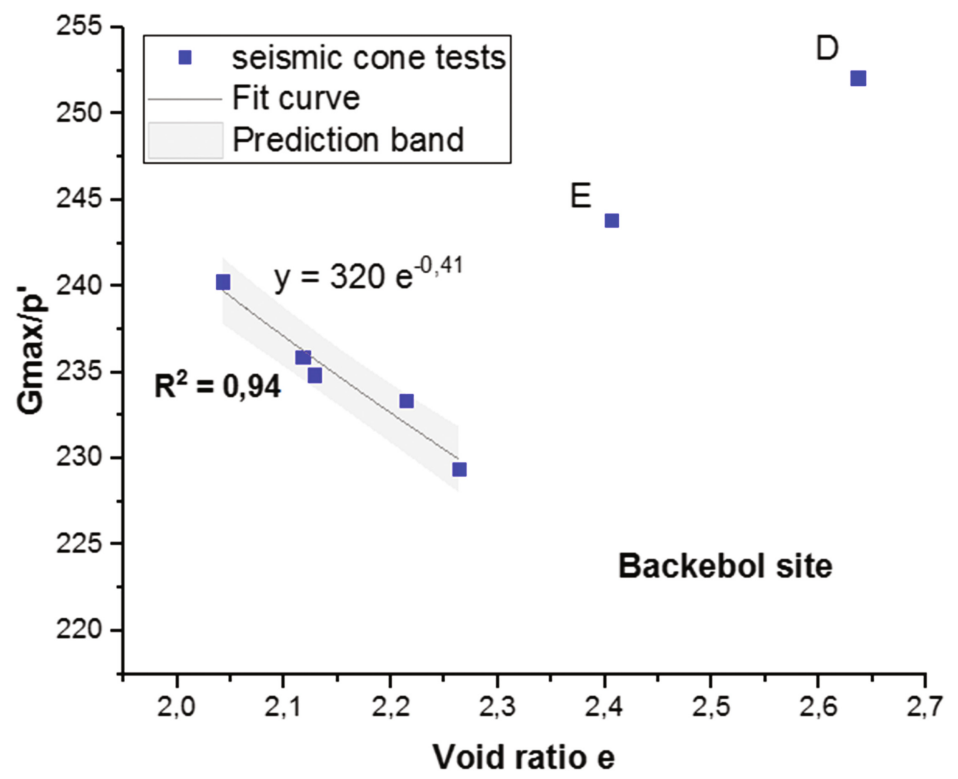

Fig. 12. Normalized small strain shear modulus versus mean effective stress for sensitive soils in Bäckebol

\subsection{Empirical Correlations for Soft Soils}

Many empirical correlations for the evaluation of $\mathrm{G}_{\max }$ have been proposed in the literature. The authors would suggest a new empirical correlation for such type of soft sensitive soils, besides of the standard proposals gathered in Table 5 .

Table 5. Selected empirical formulas for calculating $G_{\max }$ for soft soils

\begin{tabular}{l|l|l}
\hline Form of the function & Authors & Kind of soil \\
\hline G0 $=625 \cdot \frac{\left(p^{\prime} \cdot p a\right)^{0,5}}{\left(0,3+0,7 e^{2}\right)}$ & Hardin $(1978)$ & $\begin{array}{l}\text { Normally consolidated cohesive } \\
\text { soils }\end{array}$ \\
\hline $\mathrm{G} 0=625 \cdot \frac{\left(p^{\prime} \cdot p a\right)^{0,5}}{\left(e^{1,3}\right)}$ & Jamilkowski et al. (1991) & NC cohesive soils \\
\hline $\mathrm{G} 0=14,24 \cdot \mathrm{p}^{0,23} \cdot e^{-1,26}$ & $\begin{array}{l}\text { Markowska-Lech et al. } \\
(2007)\end{array}$ & Cohesive soils \\
\hline $\mathrm{G} 0=\mathrm{p}^{0,85} \cdot e^{-1,26}$ & Gabryś and Szymańsk (2015) & NC cohesive soils \\
\hline
\end{tabular}


As mentioned above, $\mathrm{G}_{\max }$ depends on a number of parameters and the void ratio is recognized as the second meaningful parameter affecting soil stiffness in combination with the effective stress level.

The collected data and the tests results indicate the possibility of estimating the small strain shear modulus in this type of soft sensitive soils from the mean effective stress and the void ratio. The authors proposed a new correlation which could be helpful in estimating the shear modulus at very small strain without the need for the shear wave velocity measurement:

$$
G_{\max }(M P a)=0,53 \cdot p^{\prime} \cdot e^{-0,93}
$$

Table 6. Laboratory fitting parameters of test soils for authors' equation

\begin{tabular}{|c|c|c|c|c|c|c|c|c|c|}
\hline \multirow{3}{*}{$\begin{array}{l}\text { Form of the } \\
\text { function }\end{array}$} & \multirow{2}{*}{\multicolumn{3}{|c|}{ Coefficient }} & \multirow{2}{*}{\multicolumn{3}{|c|}{$\begin{array}{l}\text { Standard error of } \\
\text { the coefficient }\end{array}$}} & \multirow{3}{*}{$\begin{array}{l}\text { Correlation } \\
\text { coefficient }\end{array}$} & \multicolumn{2}{|l|}{ Statistics } \\
\hline & & & & & & & & \multirow{2}{*}{$\begin{array}{l}\text { Reduced } \\
\text { Chi-Sqr }\end{array}$} & \multirow{2}{*}{$\begin{array}{l}\text { Adj. } \\
\text { R-square }\end{array}$} \\
\hline & $\mathrm{a}$ & b & $\mathrm{c}$ & $\mathrm{a}$ & $\mathrm{b}$ & $\mathrm{c}$ & & & \\
\hline$G_{\max }=a \cdot p^{\prime b} \cdot e^{c}$ & 0,53 & 1,00 & $-0,93$ & 0,15 & 0,06 & 0,14 & 0,96 & 0,530 & 0,956 \\
\hline
\end{tabular}

Table 6 shows the values of the coefficients as well as the basic fitting parameters for the proposed function (Eq. (4)). The proposed correlation explains at least $96 \%$ of the Gmax variation $\left(\mathrm{R}^{2}=0.96\right)$ (when ignoring the isolated points). It indeed very closely matches the data set. A graphical illustration of the proposed equation is illustrated in Fig. 13.

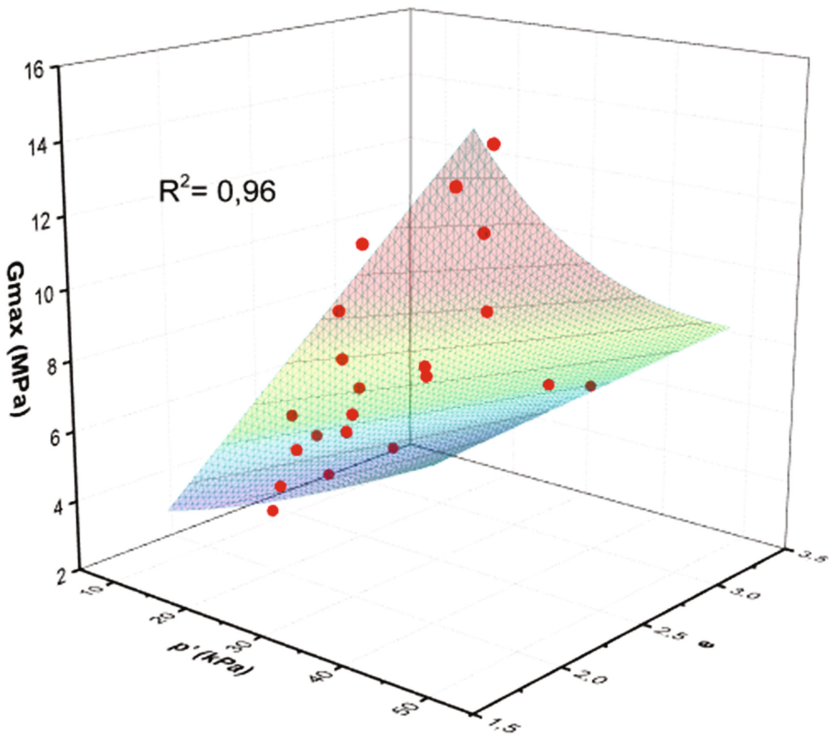

Fig. 13. Correlation of the experimental shear modulus with the mean effective stress and void ratio for sensitive soils. 
To examine the reliability of the proposed empirical equation, some standard empirical equations (Table 5) were also used to verify their suitability to the data set of each site (Figs. 14, 15, 16 and 17). As can be seen from those Figures, the authors' proposed expression fits the results of the tests for Tunis, Norrköping, Skå-Edeby and Bäckebol soft soils well.

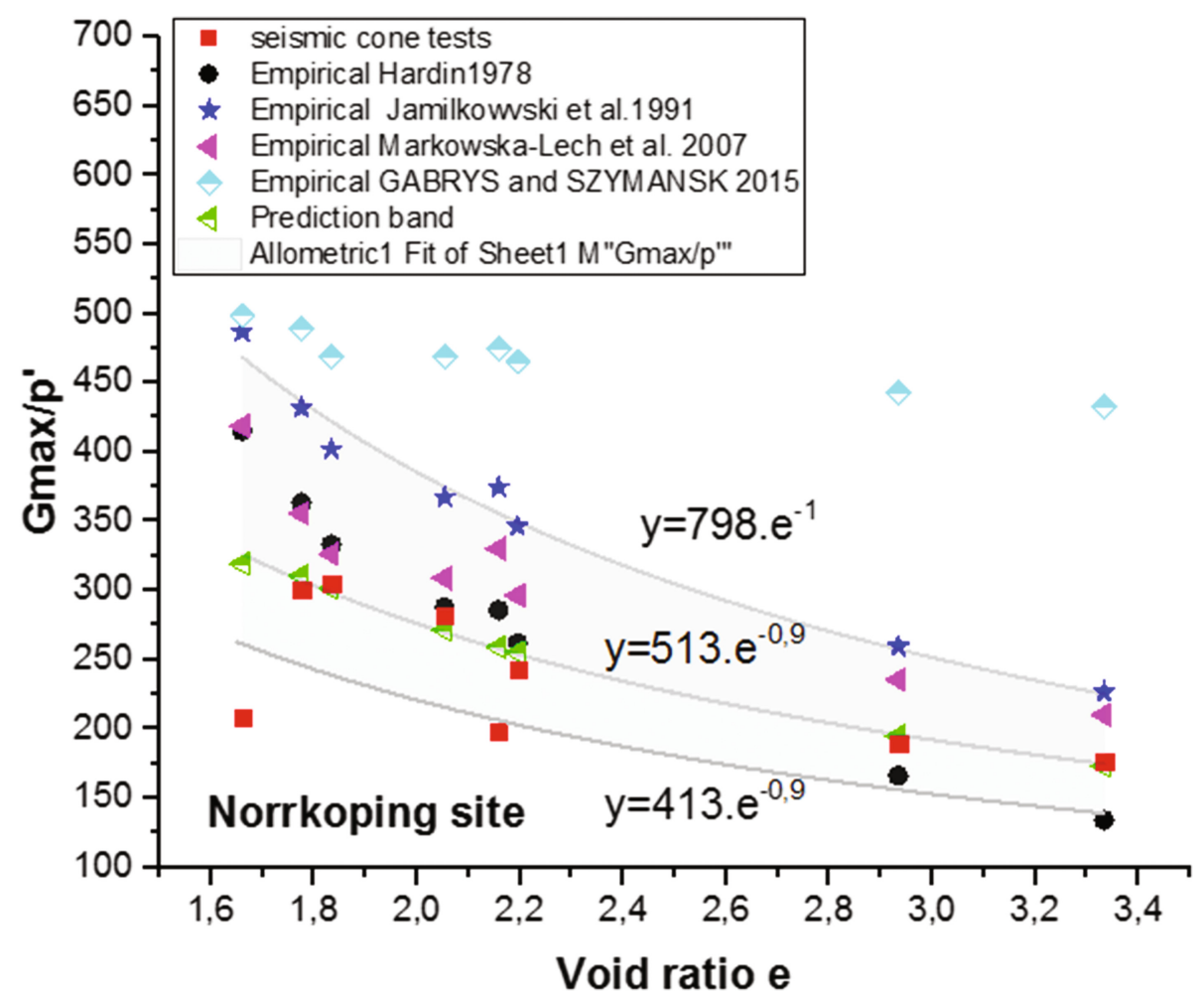

Fig. 14. Correlation of the experimental values of normalized shear modulus with the void ratio for the Norrköping sensitive soil. 


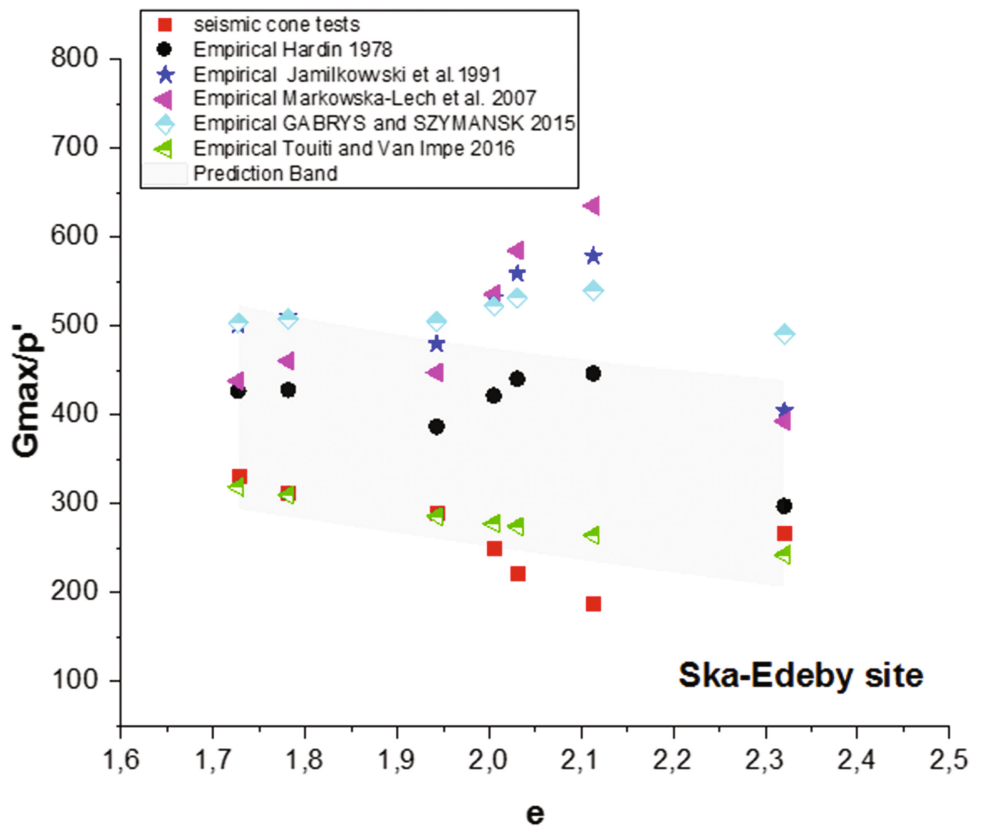

Fig. 15. The experimental and the estimated values of the normalized shear modulus with the void ratio for Skå-Edeby sensitive soil

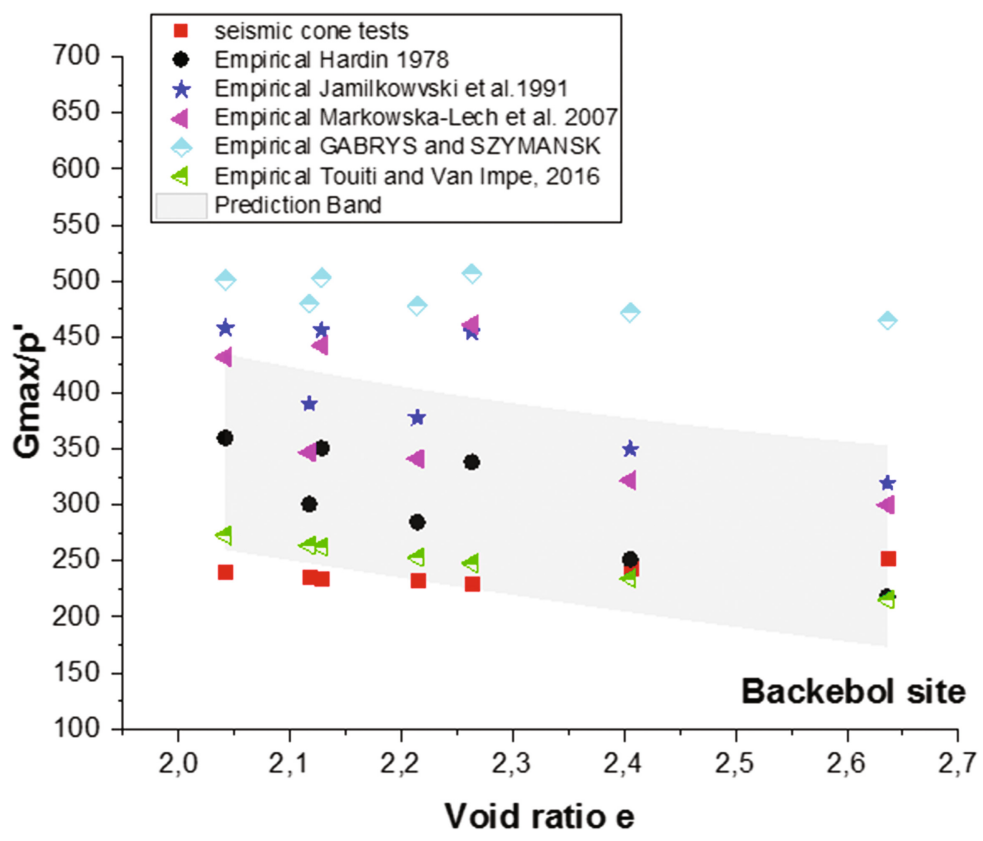

Fig. 16. The experimental and the estimated values of the normalized shear modulus with the void ratio for Bäckebol soft soil. 


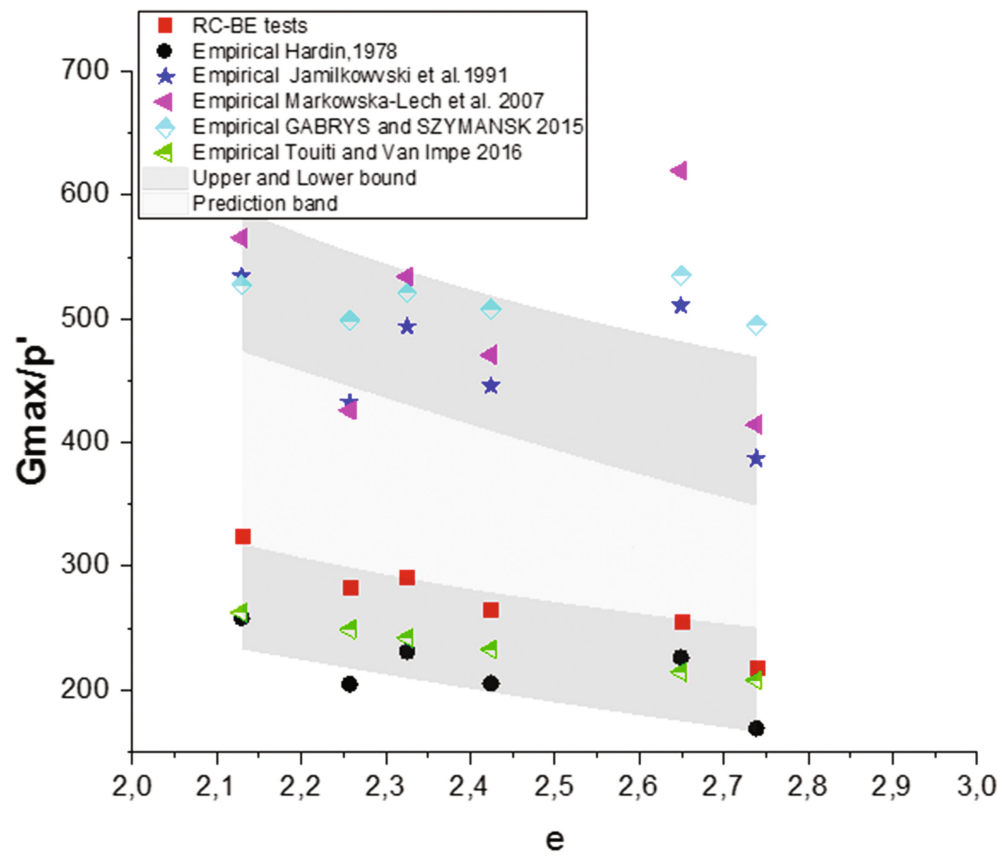

Fig. 17. The authors' experimental and the estimated values of the normalized shear modulus with the void ratio for Tunis soft soil.

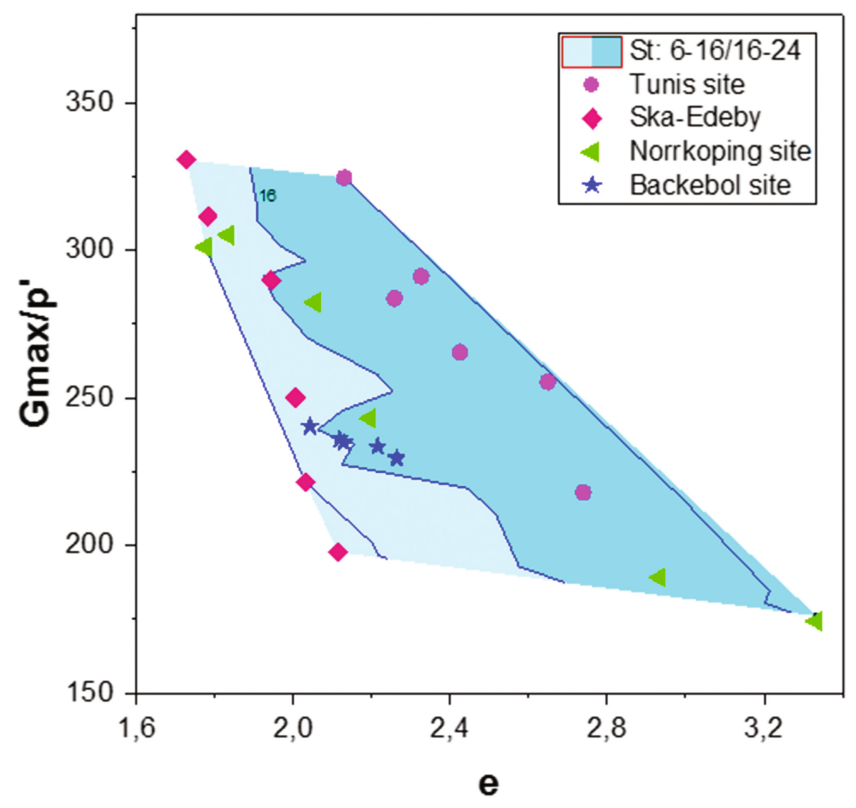

Fig. 18. The normalized small strain shear strength versus the void ratio by indicating the sensitivity range of each investigated soft soil. 
The sensitivity is obviously a meaningful parameter affecting the small strain shear modulus (Fig. 18). Consequently, soft soils with the same void ratio and mean effective stress but different sensitivity values would have different stiffness.

The proposed equation fits the data related to Tunis, Norrköping and Bäckebol soft soils a lot more than those related to Skå-Edeby soft soil as it is less sensitive (Figs. 14, 15, 16 and 17).

Obviously, we are aware that the proposed lower bound correlation requires further verification by performing further research taking into account other sensitive soils and more diverse sites.

\section{Conclusion}

The small strain shear modulus $\left(\mathrm{G}_{\max }\right)$ of soft soils from Tunis (Tunisia) and various sites in Sweden was measured by means of resonant column, Bender element and cone seismic tests. Based on these results, some conclusions can be drawn:

- In all the analyzed cases, the values of $G_{\max }$ do increase with an increase of the mean effective stress.

- The results clearly indicate that the $G_{\max }$ increases with a decreasing void ratio for most of the specimens, which is in agreement with results in literature.

- The authors proposed a suitable correlation pattern $\left(\mathrm{R}^{2}=0.96\right)$, enabling to cover up to $96 \%$ of the $\mathrm{G}_{\max }$ variation.

- The soft soil sensitivity (St) is also a meaningful parameter when describing the small strain shear modulus of soft soils, however not fully and well enough understood.

Acknowledgements. The first author would like to acknowledge that all laboratory tests were conducted at the Geotechnical Institute for Experimental Models (ISMGEO Laboratory) in Italy and thank all the staff for their assistance. We would also like to thank Prof. Larsson for permitting us to use his experimental data about the Swedish soils.

\section{References}

Schnaid, F.: Geo-characterization and properties of natural soils by in situ tests. In: Proceedings of 16th International Conference on Soil Mechanics and Geotechnical Engineering, Osaka, pp. 3-45 (2005)

Stokoe II, K.H., Rathje, E.M., Axtell, P.J.: Development of an in-situ method to measure the non linear shear modulus of soil. In: Proceedings of the 16th International Conference on Soil Mechanics and Geotechnical Engineering, Osaka, pp. 751-754 (2005)

Nash, D.F.T., Lings, M.L., Pennington, D.S.: The dependence of anisotropic go shear moduli on void ratio and stress state for reconstituted Gault clay. In: Lancellotta\&LoPresti, J. (eds.) Prefailure Deformation Characteristic of Geomaterial, pp. 229-238. Rotterdam (1999)

Benz, T.: Small-Strain Stiffness of Soils and its Numerical Consequences. Ph.D. thesis, University of Stuttgart (2007) 
Schneider, J.A., Hoyos Jr., L., Mayne, P., Macari, E.J., Rix, G.J.: Field and laboratory measurements of dynamic shear modulus of Piedmont residual soils. ASCE Geotech. Spec. Publ. 92, 12-25 (1999)

Wolski, W., Lipinski, M.J.: Site characterisation for geotechnical and environmental purposes. In: Proceedings of the XIIIth Danube-European Conference on Geotechnical Engineering, Ljubljana, pp. 129-150 (2006)

Kaâniche, A., Inoubli, M.H., Zargouni, F.: Développement d'un SIGG et réalisation d'un atlas géotechnique électronique. Bulletin Anglai deGéologie et d'environnement. Springer, Heidelberg (2000)

Touiti, L., Bouassida, M., Van Impe, W.: Discussion on the Tunis soft clay sensitivity. Geotechn. Geol. Eng. J. (2009). doi:10.1007/s10706-009-9263-2

Markowska-Lech, K., Lech, M., Szymanski, A.: Estimation of shear modulus from seismic tests on Pliocene clays. In: Proceedings of International Conference on Numerical Models in Geomechanics, London, pp. 153-157 (2007)

Larsson, R., Mulabdic, M.: Shear moduli in scandinavian clays. Swedish Geotechnical Institute, report $n^{\circ}$. 40, Linkoping, pp. 40-94 (1991) 